\title{
Study on Exceeding Budget Factors on Construction Project's Cost and Effective Control Strategy
}

\author{
Wei Li \\ Chongqing Vocational Institute of Engineering \\ (China,Chongqing402260)
}

Keywords: Construction cost; Over budget; Control strategy

\begin{abstract}
Any project requires a detailed plan before implementation, and project cost budget is the center of the whole project plan, it not only defines the total investment of the whole project, and provide a favorable basis for the investment of construction project in each stage of construction. However, not all of the construction project can be successfully completed according to plan, the construction project will be influenced by external factors in the implementation process resulting in engineering calculation cost far more than the initial cost budget. This paper briefly introduces the concept of construction cost and the significance of over budget control, and it analyzes the factors that exceed the budget of construction cost, and puts forward the corresponding control strategies for these factors.

With the high-rise buildings, each city will be more or less has some uncompleted residential flats, and these uncompleted residential flats mostly because of capital problems and lead to investors on foot. Further analysis can lead to find that the lack of investment in the construction phase, and the basic reason for the failure are that the construction budget is seriously out of line with the actual construction investment. From this, we can judge that in the construction project, the budget of the project cost is the key to whether the whole project can be completed satisfactorily. Without scientific and rational budgeting, it is difficult for the project to allocate funds in a scientific and rational way at all stages of construction which will result in a serious problem of exceeding the budget and result in economic disputes. Therefore, it is important for the whole project to find out the factors that affect the budget of the project cost and to control and manage them from the source.
\end{abstract}

\section{The Significance of Construction Cost and its over Budget Control}

The common understanding of construction cost is: all funds invested by the construction project from the initial preparation to the final completion acceptance. It consists of civil, installation, tax, reserve and other parts, and the installation includes the purchase and installation of equipment. In construction projects, there are the general construction budget estimates, construction plans budget and final accounts, and construction costs are usually used in construction drawing budget ${ }^{[1]}$.

From the above concept, we can see that the construction project cost occupies a dominant position in the entire project construction, the scientific and rational control is also has great significance: firstly, the construction project cost budget control can minimize the quantity increase in the construction stage, so as to increase investment funds which results in serious budget overruns and the whole project can not be carried out smoothly; secondly, according to the actual engineering quantity, it will be strictly controlled in the examination and approval of the budget within the scope of investment construction, and it effectively reduce the cost of the whole construction to maximize project benefits; thirdly, the various stages of the project are related to the construction engineering budget control, therefore, in the implementation process, each super budget projects should be timely feedback to find out the reasons, so as to reduce the cost that is good for the future construction of super provide experience in budget control. 


\section{Analysis of Factors on Construction Project Cost over Budget}

The Budget of Construction Project is Unreasonable. In construction project budget preparation process, there will not be the staff to the actual construction site for exploration which are directly related to the construction plans provided by the staff to prepare the budget. As the staff members do not have a thorough understanding of specific construction projects, but only in accordance with their own theoretical knowledge of budgeting, and there will be actual project beyond budget imagination. For example, if the geological staff has not detailed read the construction site survey report, it is likely that in the actual construction process, the geological conditions appear sudden, and resulting in the earthwork calculation of engineering theory far beyond the amount of budget staff; or it is not on the actual construction site survey, and the results can not be found in the construction site traffic inconvenient, these projects will lead to the completion of all once accumulation that is far beyond the numerical budget staff concluded that the serious cause of construction work stoppage or even unfinished ${ }^{[2]}$.

Market and Natural Factors have an Impact on the Cost of Construction Projects. In the construction project, the cost is the biggest material, and the price of building materials is also changing with the market demand. The construction project construction period is often a year or even several years, the materials used were widely, and staffing initial budget is compiled according to the price information, although in the preparation process of the material price change will be predicted, but it can not guarantee that all no major changes in the next few years. Market changes the current needs of materials, but it also with the local government's relevant laws, regulations, policies that have a certain relationship. And because the construction project cycle is generally longer, in the construction process, there often have floods, heavy rain, and even earthquakes and other natural factors. When the above situation occurs in the actual construction project construction, the actual project cost will exceed the budget.

The Quality of Budget Staff is not High. In the actual budget, budget staff can not timely collect construction material, and they compiled material according to the theory of knowledge learning, while ignoring the influence in the actual operation of the natural environment, market demand and construction period. The budget staff can not conclude building materials price fluctuation on anticipation, and it also ignores the field survey on the construction site, so in the process of project budget, it is prone to missing items and leakage situation which result in the entire construction project budget that is not in perfect condition.

Design Change. In the process of construction, the design change caused by the geological survey report is not detailed, and the designer's own professional knowledge is restricted, and the design defects or the willingness of the construction units are caused. The budget is in the design phase of construction work, for the engineering construction of force majeure that caused by design changes cannot be predicted, and these design changes obviously will lead to the construction project cost budget.

The Construction Site Supervision is not in Place. Construction managers often do not pay attention to the project cost, they think that the project cost is a figure, and the construction has little impact. If the construction site management stage investment of the project cost is not profound understanding, there will be staffing and material allocation unreasonable phenomenon, which often causes overcrowding and staff of waste material imagination. Once the construction project is changed, the phenomenon of manpower cost overruns will lead directly to the over budget of the whole project cost.

\section{According to the Factors of Over Budget of Construction cost, the Control Strategy is put Forward}

Reduce Design Changes. The basis of architectural design drawings include the wishes of the construction units, there are more important geological survey reports, therefore, geological prospecting work has possible more detailed, the better. According to the project total investment and detailed geological investigation report provided by the construction unit, the design unit can 
select the reasonable structure and building materials, and minimize the probability of the design change. At the same time, in the construction phase of the construction project, the construction unit should also closely link with the design and construction units to exceed the budget part of the timely feedback, as far as possible the design changes within the scope of the total investment.

Scientific and Rational Preparation of Construction Budget. Because the construction project budget has certain guidance function to the construction project, therefore, the scientific and reasonable project budget can be effectively controlled. Preparation of construction engineering budget can start from the following points: firstly, the relevant data collection of construction project cost personnel needs carefully read the study to ensure that no much access preparation of construction engineering budget and actual engineering; secondly, the cost of personnel need to conduct has a study of the construction drawings, and the construction site of the actual survey can ensure the rationality of engineering the amount of the missing items to avoid the occurrence of leakage; finally, the cost of personnel according to the current market demand and local weather conditions make appropriate adjustments to the building materials and the construction period to reduce the budget and the actual gap.

Improve the Professional Quality of Budget Staff. The professional knowledge accomplishment of the budget maker determines whether the final construction project budget is perfect and reasonable. Therefore, in order to effectively control the cost of construction projects over budget, it is necessary to improve the professional quality of budget staff. First of all, the budget personnel must master the relevant laws and regulations, engineering quantity calculation, construction materials, construction equipment and construction technology of basic engineering knowledge; secondly, the budget cost of staff to strengthen the learning and training, as much as possible to participate in training when to combine theory with practice and promotion their professional quality; finally, in the process of compiling construction budget, as much as possible to collect project information, feasible scheme and detailed research project of the geological survey report and construction drawings. The construction site of the survey, as far as possible the factors are considered once again combined with the actual situation that will be over budget control to ensure that the final preparation of the budget scientific and rational.

Control the Construction Phase. The smooth construction of construction projects, in addition to solid construction technology, but also reasonable construction management, and the scientific rationality of construction management that is directly related to the project cost. Construction management is mainly to the construction site personnel, materials, safety, technology and schedule management. Building materials accounted for a large proportion in the construction budget, therefore, management personnel filing and staffing according to the project schedule, and the expected amount compared with the actual amount, avoid the waste of material and personnel excessive phenomenon. To reduce consumption of resources needs to achieve the best economic effect to ensure the quality of construction and construction technology; according to field staff, reasonable allocation of staff to avoid the confusion of the personnel; improve their safety awareness of construction personnel, set up security warning signs in the safe place, to prevent the occurrence of major accidents; according to the site every day to work, the reasonable arrangement of construction schedule, adjusted according to weather conditions appropriate to ensure construction content, construction project completed on schedule.

\section{Conclusion}

The capital input is the most important part of the successful completion of a construction project. But any project's budget funds are rationed and cannot be arbitrarily wasted. From the above chapters, we can see that the budget of construction projects is not only related to the construction units, but also to the construction units and the design units. The construction project in the design and construction process is easy to appear over budget, therefore, only to find the factors influencing the construction cost, and these factors are controlled in order to effectively control the budget in the approval of funds within the scope. At the same time, it should also be combined with the actual situation of the construction project, analyze and control continue to explore the new 
methods of construction projects in the budget to ensure the economic benefit and social benefit of construction projects.

\section{Reference}

[1]Jieling Xu.Discussion on causes and control countermeasures of construction project cost exceeding budget[J].Modern Economic Information, 2014(07).

[2]Mingbo Zhang.Causes and control measures of construction project cost exceeding budget[J].Jiangxi Building Materials, 2015,16:256. 